\title{
Hepatocellular Malignant Neoplasm, Not Otherwise Specified: A New Name in Liver Tumors: A Brief Narrative Review of Published
}

\section{Cases}

\author{
Bita Geramizadeh $^{\text {a, b }}$ Razieh Foroughi ${ }^{a} \quad$ Alireza Shojazadeh $^{\mathrm{a}}$ \\ aDepartment of Pathology, Medical School of Shiraz University, Shiraz University of Medical Sciences, Shiraz, Iran; \\ bTransplant Research Center, Shiraz University of Medical Sciences, Shiraz, Iran
}

\section{Keywords}

Hepatocellular malignant tumor, not otherwise specified.

Hepatoblastoma $\cdot$ Hepatocellular carcinoma

\begin{abstract}
Background: Hepatocellular malignant neoplasm, not otherwise specified (HEM, NOS), is a rare liver tumor that is most commonly seen in adolescents. To the best of our knowledge, there has been no published review on this rare tumor in the English literature so far. Summary: In this review, we will discuss all reported details, including demographic findings, clinical presentations, molecular histogenesis, imaging, gross pathology and histopathology, immunohistochemical findings, treatment modalities, and outcome, of the published cases of HEM, NOS, in the liver. Key Message: Twentytwo cases of HEM, NOS, have been reported in the last 10 years in the English literature. This tumor produces a large liver mass and is characteristically seen in adolescents presenting with right upper quadrant pain. Histologically, HEM, NOS, is a nonbiliary hepatocytic tumor with a biphasic pattern, that is, a mixture of 2 components of hepatocellular carcinoma and hepatoblastoma (HBL). There is no characteristic immunohistochemical feature for this tumor. Imaging findings are also not specific. Treatment of this tumor needs extensive surgery or even liver transplantation. Most of the
\end{abstract}

cases in the literature were treated with the primary diagnosis of $\mathrm{HBL}$, so pathologists, onco-surgeons, and oncologists should get familiar with this tumor to provide better treatment options. More case series with more follow-ups are necessary for the definite determination of the outcome of this tumor as a unique entity.

(c) 2021 The Author(s).

Published by S. Karger AG, Basel

\section{Introduction}

Two of the most common malignant tumors of the liver are hepatocellular carcinoma (HCC) and hepatoblastoma (HBL). These are the only malignant tumors originated from hepatocytes [1]. HBL is commonly seen in infants and rarely seen in patients older than 4 years. HCCs are usually seen in older children and adult patients [2].

Clinicopathologic diagnosis of most of the hepatocellular tumors is straightforward; however, recently, another transitional tumor was introduced with overlapping clinical and histological features of HCC and HBL, which are most commonly reported in adolescents. Histology of these tumors is more complex and is composed of a mixture of HCC and HBL [3].
(C) 2021 The Author(s)

Published by S. Karger AG, Basel

This article is licensed under the Creative Commons AttributionNonCommercial-NoDerivatives 4.0 International License (CC BYNC-ND) (http://www.karger.com/Services/OpenAccessLicense) Usage and distribution for commercial purposes as well as any distribution of modified material requires written permission.
Bita Geramizadeh

Department of Pathology, Medical School of Shiraz University

Shiraz University of Medical Science

Zand Street, Shiraz 7194818476 (Iran) geramib@gmail.com 
Table 1. Clinicopathologic characteristics of 22 reported cases of hepatocellular malignant tumor, NOS, in the literature

\begin{tabular}{|c|c|c|c|c|c|c|c|}
\hline Author & $\begin{array}{l}\text { Age, } \\
\text { years/sex }\end{array}$ & $\begin{array}{l}\text { Clinical } \\
\text { presentation }\end{array}$ & $\begin{array}{l}\mathrm{AFP} \\
\mathrm{ng} / \mathrm{mL}\end{array}$ & $\begin{array}{l}\text { Lobe/ } \\
\text { size, } \mathrm{cm}\end{array}$ & $\begin{array}{l}\text { Pre-chemo } \\
\text { pathology diagnoses }\end{array}$ & $\begin{array}{l}\text { Neoadjuvant } \\
\text { chemotherapy }\end{array}$ & Outcome \\
\hline \multirow[t]{6}{*}{ Prokurat et al. [3] } & $9 / M$ & $\mathrm{nr}$ & $21 \mathrm{~K}$ & Right/nr & HBL & - & Died after 22 months \\
\hline & $17 / \mathrm{F}$ & $\mathrm{nr}$ & $200 \mathrm{~K}$ & Right/15 & HBL & - & Died 22 months \\
\hline & $14 / \mathrm{F}$ & $\mathrm{nr}$ & Very high & Right/15 & HBL & - & Alive after 50 months \\
\hline & $5 / \mathrm{M}$ & $\mathrm{nr}$ & $100 \mathrm{~K}$ & Right/10 & $\mathrm{nr}$ & - & Alive after 60 months \\
\hline & $11 / \mathrm{M}$ & $\mathrm{nr}$ & $>300$ & Right/5 & HBL & - & $\begin{array}{l}\text { Died on day } 13 \\
\text { post-surgery }\end{array}$ \\
\hline & $6 / \mathrm{F}$ & $\mathrm{nr}$ & $200 \mathrm{~K}$ & & na & - & Poor follow-up \\
\hline Seng et al. [5] & $8 / \mathrm{M}$ & Abdominal distention & $550 \mathrm{~K}$ & Multiple & HEM, NOS & + & Alive after 3 years \\
\hline \multirow[t]{6}{*}{ Zhou et al. [2] } & $4.5 / \mathrm{M}$ & Acute abdomen & $25 \mathrm{~K}$ & Right/11.3 & HBL + focal HCC-like & + & Alive after 11 years \\
\hline & $12.5 / \mathrm{M}$ & Abdominal pain & $980 \mathrm{~K}$ & Right/10 & HEM, NOS & + & Alive after 8.8 years \\
\hline & $4 / \mathrm{M}$ & Abdominal pain & $301 \mathrm{~K}$ & Right/5 & HEM, NOS & + & Alive after 7.5 years \\
\hline & $9 / M$ & Abdominal pain & $439 \mathrm{~K}$ & Right/4.5 & HEM, NOS & + & Alive after 9 years \\
\hline & $5 / \mathrm{M}$ & Abdominal pain & $80 \mathrm{~K}$ & Right/9 & HBL + focal HCC-like & + & Alive after 7.9 years \\
\hline & $7 / \mathrm{M}$ & Abdominal pain & $70 \mathrm{~K}$ & Right $/ 4.3$ & HEM, NOS & + & Alive after 6.1 years \\
\hline
\end{tabular}

nr, not reported; HBL, hepatoblastoma; HEM, NOS, hepatocellular malignant tumor, not otherwise specified; HCC, hepatocellular carcinoma; OLT, orthotopic liver transplant.

In the older literature, these tumors were considered as "transitional liver cell tumors," but in 2014, another provisional title was proposed by an International Pediatric Liver Tumor Consensus Classification, that is, "hepatocellular malignant tumor (HEM), NOS.” The reason for this change was because of genetic analysis, which showed genomic instability and telomerase reverse transcriptase (TERT) promoter mutation, which are molecular characteristics of aggressive HBL with HCC features [4]. An accurate diagnosis of this entity is important because of the challenging and controversial chemothera- peutic regimens [2]. In this study, we try to review all the clinicopathologic characteristics of the published cases of this tumor as a new entity in the English literature.

\section{Materials and Methods}

Case reports and case series published in English in the last 20 years have been collected by searching PubMed, Google, and Google Scholar. The key words for the search were "liver" and different names of the tumor, that is, "hepatocellular malignant tumor, NOS" and "transitional liver cell tumors," and "mixed hepa- 
Table 2. Immunohistochemical findings of the reported cases of HEM, NOS

\begin{tabular}{lccc}
\hline Marker & $\begin{array}{l}\text { Reported } \\
\text { cases }\end{array}$ & Positive & Percentage \\
\hline B-Catenin & 20 & 20 & 100 \\
Glypican-3 & 13 & 13 & 100 \\
SALL4 & 11 & 11 & 100 \\
Nuclear staining of TERT & 11 & 9 & 81.8 \\
HepPar1 & 2 & 2 & 100 \\
AFP & 8 & 7 & 87.5 \\
Cam 5.2 & 1 & 1 & 100 \\
EMA & 7 & 1 & 14.3 \\
CK19 & 7 & 1 & 14.3 \\
P53 & 7 & 1 & 14.3 \\
\hline
\end{tabular}

HEM, NOS, hepatocellular malignant tumor, not otherwise specified; TERT, telomerase reverse transcriptase; AFP, alphafetoprotein.

toblastoma and hepatocellular carcinoma." Twenty-two cases were found in the English literature. Table 1 shows the clinical characteristics of these 22 cases.

\section{Results}

Tables 1-3 show the clinicopathologic characteristics of these 22 reported and published cases with hepatocellular malignant neoplasm, not otherwise specified (HEM, NOS) in the literature.

\section{Demographic Findings and Clinical Presentation}

Sixteen patients were male, and 6 were female (male/ female $=16 / 6)$. The median age at the diagnosis was 8 years (range: $4-23$ years). The age range was $4-18$ years, except for one, who was 23 years old.

Majority of the patients presented with right upper quadrant abdominal pain (10 cases). Three patients $(13.6 \%)$ were referred with a sudden onset of severe abdominal pain (acute abdomen) associated with nausea/ vomiting due to tumor rupture [2]. One patient had no pain and presented with abdominal distention due to a firm epigastric mass for a 1-month duration [5]. In the remaining 5 cases, presenting symptoms have not been mentioned $[3,6]$.

\section{Laboratory Findings}

Liver enzymes were reported as normal in only 2 patients $[7,8]$. One study reported anemia, leukocytosis (with neutrophilia), and elevated ESR [7].
Alpha-fetoprotein (AFP) level was measured in all cases except one. It was significantly elevated with a range of $21,000-1,280,000 \mathrm{ng} / \mathrm{mL}$. Other tumor markers such as CA 19-9 and CEA were reported as normal in 1 case report [8].

\section{Imaging Studies}

In the majority of the previous cases, computed tomography (CT) scan was the main perioperative imaging modality that was used to determine the tumor characteristics, including the size and extension of the tumor. The reported CT scan findings showed that the tumors were large in size, with peripheral enhancement and central necrosis. Thirteen tumors were multifocal. The size of the reported tumors was $4.3-15 \mathrm{~cm}$, and $>60 \%$ of the reported tumors were $>10 \mathrm{~cm}$. In 2 of the previous cases, magnetic resonance imaging (MRI) was reported as the main imaging modality. The reported MRI findings in these 2 cases were multilobulated large and heterogeneous solid liver tumor with low signal intensity on T1-weighted and high signal intensity on T2-weighted images. In gadolinium-enhanced MRI, slight enhancement was reported, which was less than the normal liver parenchyma $[6,7]$.

\section{Past Medical History}

In one of the reported cases, the previous history of medulloblastoma was noted ( 26 months before the liver tumor) [6]. In 3 patients, a history of prematurity has been reported $[2,5]$. No other positive past medical history was reported.

\section{Pathologic Findings}

\section{Macroscopic findings}

In only one of the reported cases, the gross description was mentioned as a well-circumscribed tumor with 2 different areas: a pink to yellow-tan lobulated lesion with central areas of hemorrhage representing $70 \%$ of the tumor and a rubbery yellow-tan lesion lacking central hemorrhage in remaining $30 \%$ of the tumor [8].

\section{Microscopic findings}

Among the 22 reported cases, 17 patients had a liver biopsy or primary tumor resection before chemotherapy. Twelve cases demonstrated a heterogeneous malignant tumor with a mixture of histological features of both HBL and HCC, and 5 cases reported a uniform population of cells with abundant cytoplasm, consistent with typical fetal HBL. Among those cases that were categorized as HEM, NOS, the tissue diagnosis of 6 patients remained 
Table 3. Summary of the presentation of 22 reported cases of HEM, NOS

\begin{tabular}{ll}
\hline Characteristic & Most common findings \\
\hline Sex (F/M) & $6 / 16$ \\
\hline Age (range), years & $4-23$ \\
\hline Most common clinical presentation & RUQ pain \\
\hline Most common imaging characteristic & A large solid tumor of the liver with peripheral enhancement and central necrosis \\
\hline AFP (range), ng/mL & $21,000-1,280,000$ \\
\hline Pre-chemo pathology diagnosis & HEM, NOS: 13 \\
& $\begin{array}{l}\text { HBL: } 5 \\
\text { nr: } 4\end{array}$ \\
\hline Post-chemo pathology diagnosis & HEM, NOS: 16 \\
& HCC-like: 2 \\
\hline Histological findings & nr: 3 \\
\hline Positive immunohistochemical markers & Heterogeneous and complex with areas similar to HBL and areas similar to HCC \\
\hline Outcome (free of disease/died) & $\beta$-Catenin and glypican-3 \\
\hline
\end{tabular}

HEM, NOS, hepatocellular malignant tumor, not otherwise specified; AFP, alpha-fetoprotein; HBL, hepatoblastoma; nr, not reported; HCC, hepatocellular carcinoma.

the same after chemotherapy. However, 2 of them changed to HCC-like features, 1 converted to HBL, 1 turned to complete necrosis, and 2 were not available anymore. For all of those patients with pre-chemotherapy tissue diagnosis of HBL, the diagnosis of HEM, NOS, was confirmed after chemotherapy. The diagnosis has been made by the presence of alternative areas very similar to fetal/embryonal type HBL with areas with HCC-like features, that is, acinar pattern and macrotrabecular pattern, as well as the presence of necrosis, mitosis, and atypical cells containing Mallory bodies. Areas of hepatocyte-like cells were reported with clear cell cytoplasm interspersed with foci of eosinophilic or amphophilic (dark) cells, and bile formation. Pre-chemotherapy pathology diagnoses of 4 cases were not available; however, their post-chemotherapy pathologic characteristics were in favor of HEM, NOS.

\section{Immunohistochemistry and Molecular Studies}

Table 2 shows the frequency of positive markers in the tumor tissue of HEM, NOS, according to the number of cases tested and reported in the previous studies. The most common IHC markers were $\beta$-catenin and glypican, which were most commonly positive in the HEM, NOS cases. $\beta$-Catenin has been reported to be strongly positive in the cytoplasm and membranous. SALL4 has been re- ported to be positive in the majority of the reported cases $[2,3]$. TERT promoter mutations were also reported to be positive in the majority of the cases [2]. AFP was reported as positive in the tumor cells ( $<5 \%$ up to $30 \%)$ [3].

\section{Treatment}

In all of the reported cases, surgical excision of the tumor was performed, except for a case from the study of Prokurat et al. [3], which had a poor follow-up. In 7 cases, the large size of the tumor or extensive recurrence prompted liver transplantation $[2,3]$.

In the majority of the cases, preoperative neoadjuvant chemotherapy, surgical excision, and postoperative chemotherapy have been the treatment modalities, but 2 patients did not receive postoperative chemotherapy [3] and 1 patient did not receive chemotherapy at all [8]. In the majority of the patients, chemotherapy was similar to the established HBL regimen, consisting of C5VD (cisplatin +5 -fluorouracil + vincristine + doxorubicin) and PLADO (cisplatin + doxorubicin) [1-8].

\section{Outcome and Follow-Up}

Fourteen of the 22 reported cases were alive and free of disease after a median follow-up of 5.1 years (range: $1.2-11.8$ years), 1 was alive with partial control of the dis- 
ease, 1 had recurrence and metastasis at last follow-up after 2 months, 1 patient was lost during follow-up, and 5 patients died. One of them died 13 days after surgery because of postoperative complications and liver failure [3].

In 1 patient, HEM, NOS, has been the second malignancy after the treatment of medulloblastoma, who died 2 months after surgical resection [6]. Three other patients died $>1$ year after the last surgery with extensive vascular dissemination and metastasis to the lung and brain [3].

\section{Conclusions}

HEM, NOS, with the previous terminology of transitional liver cell tumor is a rare tumor which mostly occurs in adolescents presenting with abdominal pain and very high titers of AFP as well as large liver tumors $(>10 \mathrm{~cm})$. The main histological characteristic of this tumor is overlapping features of HBL and HCC, so most of these tumors have been diagnosed as HBL in the small biopsies before complete resection.
The tumor is aggressive and needs extensive surgery, extended resection, and even liver transplantation as well as neoadjuvant and postsurgical chemotherapy. Molecular markers like TERT, which are positive in aggressive HBL, were reported in the patients with HEM, NOS [4, 9-13]. Pathologists should be familiar with the histomorphologic features of this tumor because there are no specific clinical or imaging findings.

\section{Conflict of Interest Statement}

The authors have no conflicts of interest to declare.

\section{Funding Sources}

There was no funding support for this study.

\section{Author Contributions}

B.G.: idea for the manuscript, literature search, and writing the manuscript. R.F.: literature search and writing the manuscript. A.S.: literature search.

\section{References}

1 Darbari A, Sabin KM, Shapiro CN, Schwarz $\mathrm{KB}$. Epidemiology of primary hepatic malignancies in U.S. children. Hepatology. 2003; 38(3):560-6.

2 Zhou S, Venkatramani R, Gupta S, Wang K, Stein JE, Wang L, et al. Hepatocellular malignant neoplasm, NOS: a clinicopathological study of 11 cases from a single institution. Histopathology. 2017;71(5):813-22.

3 Prokurat A, Kluge P, Kościesza A, Perek D, Kappeler A, Zimmermann A. Transitional liver cell tumors (TLCT) in older children and adolescents: a novel group of aggressive hepatic tumors expressing beta-catenin. Med Pediatr Oncol. 2002;39(5):510-8.

4 Eichenmüller M,, Trippel F, Kreuder M, Beck A, Schwarzmayr T, Häberle B, et al. The genomic landscape of hepatoblastoma and their progenies with HCC-like features. J Hepatol 2014;61(6):1312-20.

5 Seng MS, Berry B, Karpelowsky J, Thomas G, Mews C, Stormon M, et al. Successful treatment of a metastatic hepatocellular malignant neoplasm, not otherwise specified with chemotherapy and liver transplantation. Pediatr Blood Cancer. 2019;66(4):e27603.

6 Katzilakis N, Tsirigotaki M, Stratigaki M, Kampouraki E, Athanasopoulos E, Markaki $E A$, et al. Second malignant neoplasms in children and adolescents treated for blood malignancies and solid tumors: a single-center experience of 15 years. Indian J Med Paediatr Oncol. 2018;39:483-7.

7 Ozcan HN, Oguz B, Salim T, Talim B, Haliloglu M. A rare malignant hepatic tumor of childhood: transitional liver cell tumor revisited. JBR-BTR. 2015;98(2):79-81.

8 Ertel AE, Fu B, Shah SA. Mixed transitional liver cell tumor in a 23-year-old female: a case report. Semin Roentgenol. 2016 Apr;51(2): 123-5.

9 Katzilakis NTsirigotaki M, Stratigaki M, Kampouraki E, Athanasopoulos E, Markaki EA, et al. Second malignant neoplasms in children and adolescents treated for blood malignancies and solid tumors: a single-cen- ter experience of 15 years. Indian J Med Paediatr Oncol. 2018;39:483-7.

10 Canberk S, Uludokumaci A, Sonmez C, Cakalir C, Gulsen F, Ozbay G. Mixed hepatocellular carcinoma and hepatoblastoma: cytohistopathologic findings and differential diagnosis. Acta Cytol. 2013;57(1):91-5.

11 Papry A, Kamal M, Khalid MS. Hepatoblastoma in a child with dextrocardia and possible histopathological alteration reminiscent of hepatocellular carcinoma after neoadjuvant chemotherapy. Clin Case Rep. 2018 Apr 17; 6(6):1070-3.

12 López-Terrada D, Alaggio R, de Dávila MT, Czauderna P, Hiyama E, Katzenstein H, et al. Towards an international pediatric liver tumor consensus classification: proceedings of the Los Angeles COG liver tumors symposium. Mod Pathol. 2014;27(3):47291.

13 Chavhan GB, Siddiqui I, Ingley KM, Gupta AA. Rare malignant liver tumors in children. Pediatr Radiol. 2019;49(11):1404-21. 